\title{
EFEITO DA INCLUSÃO DE FONTES LIPÍDICAS NA DIETA DE CABRAS EM LACTAÇÃO SOBRE OS PARÂMETROS SANGUÍNEOS ${ }^{1}$
}

\author{
Effect of fat source inclusion in the diet of lactating goats on blood parameters \\ Guilherme de Lira Sobral Silva², Aderbal Marcos de Azevêdo Silva ${ }^{3}$, Giovanna Henriques Nóbrega ${ }^{4}$, \\ Solange Absalão Azevedo ${ }^{5}$, José Morais Pereira Filho ${ }^{6}$, Rodrigo de Souza Mendes ${ }^{7}$
}

\begin{abstract}
RESUMO
Conduziu-se o estudo do perfil metabólico, com o objetivo de avaliar o estado nutricional ou possíveis distúrbios metabólicos que podem comprometer a saúde e, consequentemente, o desempenho do rebanho. No presente trabalho foi avaliado o perfil metabólico de cabras em lactação, submetidas a dietas com diferentes fontes de lipídios. Foram utilizadas 16 cabras da raça Saanen com peso vivo médio de $35 \mathrm{Kg}$ e produção média diária de $1,2 \mathrm{~kg}$ de leite, distribuídas em quadrado latino com três repetições. Os tratamentos experimentais consistiram nas seguintes dietas: sem suplementação lipidica (TC); semente de faveleira (SF); torta de faveleira (TF) e caroço de algodão (CA). O experimento foi desenvolvido em quatro períodos experimentais de 14 dias, sendo 10 dias de adaptação à dieta e quatro dias de coleta de dados. No último dia de cada período foram coletadas amostras de sangue. A inclusão de semente de oleaginosa na dieta de cabras em lactação diminuiu o consumo de matéria seca por unidade metabólica (CMSU) e consumo de proteína bruta por unidade metabólica (CPBU). Dentre os quatro tratamentos não se observou diferença significativa no que se refere à concentração sérica de uréia, creatinina, GGT (gama glutamiltransferase), cálcio, fósforo, magnésio e glicose. Os níveis séricos de albumina dos animais que receberam TF foram maiores $(\mathrm{P}<0,05)$ do que os animais do grupo controle. Este trabalho sugere que as fontes de oleaginosas podem ser utilizadas na suplementação lipídica de cabras Saanen em lactação, entretanto animais alimentados com TF apresentaram um perfil metabólico mais saudável em função da suplementação lipídica.
\end{abstract}

Termos para indexação: Caprinos leiteiros, faveleira, perfil protéico, manejo alimentar.

\section{ABSTRACT}

The study of the metabolic profile has as objective to evaluate the nutritional status or possible metabolic disturbances that can damage the health and consequently the herd performance. In this work, the metabolic profile of lactating goats was evaluated, submitted to diets with different fat sources. 12 Saanen goats with BW of $35 \mathrm{~kg}$ and daily milk production of $1,2 \mathrm{~kg}$ were used, distributed into a Latin square with three repetitions. The diet comprised, without fat supplementation, TC (control) and with fat supplementation: SF (favelone seed); TF (favelone cake) and CA (cotton seed).The experiment was developed in four experimental periods of 14 days, with 10 days of adaptation to diets and four days for samples collection. In the last day of each period were collected blood samples. The inclusion of oleaginous seed into the lactating goats' diet decreased the dry matter consumption for metabolic unit (CMU) and consumption of crude protein for metabolic unit (CPMU). No significant differences in serum urea, creatinine, GGT (gamma glutamyltransferase), calcium, phosphorus, magnesium or glucose values were noticed in any of the four treatments. The serum levels of albumin in the animals that received TF were higher $(\mathrm{P}<0.05)$ than the animals of the control group. This work suggests that the oleaginous sources can be used as fat supplementation of lactating Saanen goats; however, animals fed the TF showed a healthier metabolic profile due to the fat supplement.

Index terms: Lactating goats, favelone, protein profile, management feed.

(Recebido em 29 de agosto de 2008 e aprovado em 7 de outubro de 2009)

\section{INTRODUÇÃO}

Na região semiárida do Nordeste do Brasil os caprinos constituem excelente opção de produção pecuária pela sua resistência e capacidade de adaptação frente às condições ali apresentadas. Outros fatores que vêm contribuindo para o crescimento da caprinocultura no país é a grande procura por seus produtos (carne e leite) e derivados, por serem mais saudáveis, acarretando assim maior valorização dos mesmos e, consequentemente, melhor remuneração para o produtor.

Embora autores tenham mostrado a possibilidade de lipídios causarem problemas hepáticos (Jenkins, 1993),

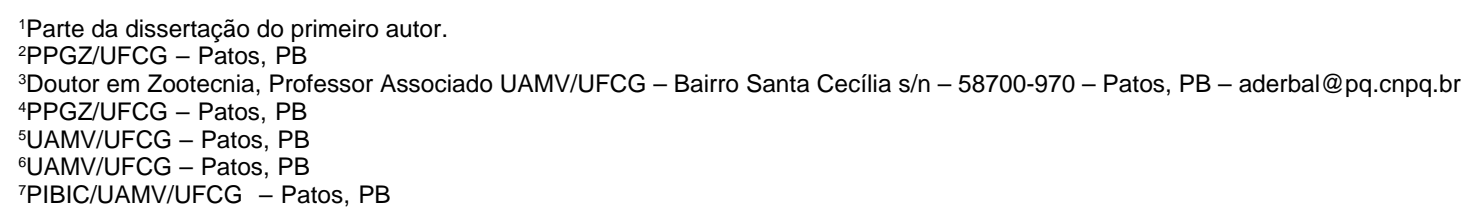


a adição de $6 \%$ de óleo de canola na dieta de cabras Alpinas não afetou a produção de leite (Mir et al., 1999), e a utilização de semente de açafrão (na quantidade de 1,9 a 4,4\%) apresentou bom efeito sobre a reprodução de fêmeas bovinas (Lammoglia et al., 2000). O uso de fontes lipídicas na ração eleva a sua densidade energética e a eficiência metabólica do animal com resultado positivo sobre a produção de leite em vacas (Avila et al., 2001).

A intensificação dos sistemas de exploração para alcançar a rentabilidade almejada aumentou também os riscos de ocorrência de transtornos metabólicos na cabra, em função de desequilíbrios entre o aporte de nutrientes ao organismo, a capacidade de metabolização desses componentes e o nível de produção alcançado (Mundim et al., 2007). O que torna vulnerável quando técnicas e práticas de manejo não são conduzidas de maneiras adequadas, sendo necessário o acompanhamento da saúde animal.

A avaliação do perfil metabólico dos animais de produção é de extrema importância no monitoramento dos distúrbios metabólicos e da funcionalidade dos órgãos vitais para a produção de leite, como é o caso do fígado (Wittwer, 2000), principalmente quando se avaliam fontes não convencionais de lipídios.

Dentre as espécies florestais ocorrentes na Caatinga nordestina, sobressai-se a faveleira (Cnidoscolus phyllacanthus, Pax e K. Hoffm.), planta da família Euforbiaceae conhecida pela sua rusticidade. As suas folhas maduras e a sua casca servem de forragem aos caprinos, ovinos e asininos, e as suas sementes são consumidas por animais de criação e pelo homem, sob a forma de óleo e farinha rica em minerais e proteína. Suas sementes oleaginosas, ramas e casca são ricas em proteína, conferindo-lhe um bom potencial alimentício e forrageiro (Bezerra, 1972).

Dessa forma, a pesquisa de fontes lipídicas, a partir de plantas nativas como a faveleira (Cnidoscolus phyllacanthus, Pax e K. Hoffm), em substituição ao caroço de algodão (Gossypium hirsutum), tradicionalmente usado na alimentação de ruminantes, surge como alternativa para os produtores.

Neste trabalho, objetivou-se avaliar a suplementação dietética com semente de faveleira, subproduto da extração do óleo da semente de faveleira (torta) e caroço de algodão sobre as variáveis sanguíneas de cabras em lactação.

\section{MATERIAL E MÉTODOS}

O experimento foi realizado na Universidade Federal de Campina Grande no Setor de Caprinocultura do Centro de Saúde e Tecnologia Rural, e as análises do sangue, no Laboratório de Patologia Clínica do Hospital Veterinário, localizado no município de Patos (PB) cidade incrustada no Sertão Paraibano.

Foram utilizadas 16 cabras da raça Saanen aos 45 dias de lactação, com peso vivo de $35,0 \mathrm{~kg}$ e produção média diária de $1,2 \mathrm{~kg}$ de leite. As dietas dos animais foram ajustadas para atender às necessidades preconizadas pelo Agricultural and Food Research Council-AFRC (1998) para cabras em lactação com uma relação volumoso:concentrado de 40:60. O volumoso fornecido foi capim elefante (Pennisetum purpureum, Schum. cv. Mott) e o concentrado composto de fubá de milho, farelo de soja, uréia, calcário e núcleo mineral. Os tratamentos receberam as seguintes denominações: $\mathrm{TC}($ controle $)=$ sem suplementação; $\mathrm{SF}=$ semente de faveleira; $\mathrm{TF}=$ torta de faveleira; $\mathrm{CA}=$ caroço de algodão. A composição percentual e química das rações é apresentada na Tabela 1.

Os animais foram everminados e pesados antes de iniciar o experimento e colocados em baias individuais, providas de bebedouros automáticos e comedouros. As dietas foram fornecidas ad libitum, individualmente e de maneira a permitir pelo menos $10 \%$ de sobras, os animais foram alimentados individualmente às 6 e 18 horas, recebendo a ração concentrada juntamente com a forragem. $\mathrm{O}$ experimento foi desenvolvido em quatro períodos experimentais de 14 dias, sendo 10 dias de adaptação à dieta e quatro dias de coleta de dados. No último dia de cada período, foram coletadas amostras de sangue $(9 \mathrm{~mL})$ por punção da veia jugular logo após a ordenha, em tubos "vacutainers". As amostras foram deixadas a coagular por um período de até 30 minutos, centrifugadas a $2500 \mathrm{rpm}$; as alíquotas foram colocadas em eppendorffs e armazendadas a $-20^{\circ} \mathrm{C}$ até a realização das dosagens bioquímicas (uréia, creatinina, albumina, proteínas totais, aspartato aminotransferase (AST), gama-glutamiltransferase (GGT), glicose, colesterol total, triglicerideos, cálcio, fósforo e magnésio) por meio de kits comerciais e analisador bioquímico semiautomático.

Os dados dos experimentos foram analisados em quadrados latinos 4 x 4, com três repetições. Cada animal, em cada período, correspondeu a uma unidade experimental, totalizando 48 unidades experimentais. As análises de todas as amostras foram realizadas em duplicata. O modelo estatístico incluiu efeitos de tratamento, quadrado latino, animal dentro do quadrado latino e período. As análises estatísticas foram feitas adotando-se o procedimento PROC GLM do SAS (SAS Institute, 1999) e, quando significativas, analisadas pelo teste de Tukey a $5 \%$ de probabilidade. 
Tabela 1 - Composição das dietas experimentais com base na matéria seca (MS).

\begin{tabular}{lcccc}
\hline & \multicolumn{4}{c}{ Tratamentos } \\
\cline { 2 - 5 } Composição percentual (\%MS) & TC & SF & TF & CA \\
\hline Capim elefante & 39,80 & 39,57 & 39,41 & 39,42 \\
Fubá de milho & 40,18 & 36,75 & 35,73 & 31,60 \\
Farelo de soja & 16,83 & 15,62 & 11,05 & 12,89 \\
Semente de faveleira & 0,00 & 4,86 & 0,00 & 0,00 \\
Torta de faveleira & 0,00 & 0,00 & 10,61 & 0,00 \\
Caroço de algodão & 0,00 & 0,00 & 0,00 & 12,89 \\
Uréia & 0,18 & 0,18 & 0,18 & 0,18 \\
Calcário calcítico & 1,84 & 1,84 & 1,84 & 1,84 \\
Núcleo mineral & 1,17 & 1,17 & 1,17 & 1,17 \\
\hline \multicolumn{1}{c}{ Composição química (\%) } & & & \\
Matéria seca & 59,63 & 63,07 & 60,11 & 60,23 \\
Proteína bruta & 18,70 & 19,23 & 18,43 & 19,51 \\
Extrato etéreo & 5,13 & 6,87 & 6,66 & 6,45 \\
Fibra em detergente neutro & 35,57 & 38,21 & 39,08 & 41,52 \\
Cinzas & 5,99 & 5,98 & 5,93 & 6,08 \\
Matéria orgânica & 90,83 & 90,77 & 90,87 & 90,73 \\
Carboidratos não fibrosos & 34,61 & 29,71 & 29,90 & 24,44 \\
Carboidratos totais & 70,18 & 68,98 & 67,93 & 65,96 \\
Cálcio & 1,57 & 1,56 & 1,53 & 1,60 \\
Fósforo & 0,5 & 0,5 & 0,4 & 0,6 \\
Energia bruta (kcal/kg) & 4253 & 4326 & 4369 & 4378 \\
\hline
\end{tabular}

TC - controle; SF - semente de faveleira; TF - torta de faveleira; CA - caroço de algodão.

\section{RESULTADOS E DISCUSSÃO}

Os valores médios do consumo de matéria seca, proteina bruta $\left(\mathrm{g} / \mathrm{dia}\right.$ e $\left.\mathrm{g} / \mathrm{kg}^{0,75}\right)$ e das variáveis proteínas totais, albumina, uréia, creatinina, GGT e AST no sangue são apresentadas na Tabela 2. Comparando-se os quatro tratamentos não se observou diferença significativa no que se refere à uréia, creatinina, e GGT .

A inclusão de semente oleaginosa na dieta de cabras em lactação representou um consumo de lipídios da ordem de 85,78 e $113(\mathrm{~g})$ para semente de faveleira, torta de faveleira e caroço de algodão, respectivamente e $73(\mathrm{~g})$ para o tratamento controle. Essa maior ingestão de lipídios provocou menores consumos de MS $\left(\mathrm{g} / \mathrm{kg}^{0,75}\right)$ e de PB (g/ $\mathrm{kg}^{0,75}$ ) pelos animais que receberam as dietas com sementes oleaginosas.

Relacionando os dados de consumo de MS, PB (g/ dia e $\mathrm{g} / \mathrm{kg}^{0,75}$ ) e os parâmetros sanguíneos de uréia e albumina, observou-se (Tabela 2) que o grupo que recebeu torta de faveleira apresentou um menor consumo de MS e
PB (g/dia e g/ $\left.\mathrm{kg}^{0,75}\right)$ do que o grupo controle $(\mathrm{TC})(\mathrm{P}<0,05)$. Em contrapartida, os resultados séricos de uréia plasmática não diferiram estatisticamente $(\mathrm{P}>0,05)$, diferentemente do que ocorreu com a albumina, onde se observa uma diferença estatística $(\mathrm{P}<0,05)$ entre o grupo que recebeu torta de faveleira (TF) e o tratamento controle (TC), o que não ocorreu entre os tratamentos com semente de oleaginosas (SF, TF e CA). Esse resultado sugere que o tratamento com torta de faveleira teve melhor aproveitamento da proteína, uma vez que a albumina é considerada o indicador mais sensível para avaliar o estado nutricional proteico, considerando-se que a sua concentração pode ser alterada pela qualidade da alimentação (González, 2000).

Os valores médios de nitrogênio ureico sérico desse experimento se apresentaram maiores do que aqueles considerados de referência por Boyd (1983) e, dos resultados obtidos por Silva et al. (2007) trabalhando com diferentes fontes de suplementação lipídica, mas foram similares aos observados por Cortada et al. (2000) para 
carneiros adultos alimentados com elevados níveis de proteína bruta. Os níveis séricos de creatinina, bem como os de GGT e AST, permaneceram dentro dos valores normais (Boyd, 1983).

González \& Silva (2003) relacionam as atividades das enzimas AST e GGT como biomarcadores sanguíneos de grande valor para avaliar distúrbios metabólicos e funcionamento hepático. Nesse experimento, os valores séricos dessas enzimas, juntamente com os valores de proteínas totais, indicam que não houve transtornos hepáticos ao longo do experimento.

Os resultados deste trabalho apresentam diferença significativa entre os valores séricos de proteínas totais dos animais do grupo testemunha $(5,94 \mathrm{~g} / \mathrm{dL})$ em relação aos que receberam caroço de algodão $(6,41 \mathrm{~g} / \mathrm{dL})$ e dos que receberam torta de faveleira $(6,34 \mathrm{~g} / \mathrm{dL})$.

Os dados referentes a glicose, triglicérideos e colesterol total encontram-se na Tabela 3.

O nível de glicose plasmático é o indicador menos expressivo do perfil para avaliar o estado nutricional energético, decorrente da insensibilidade da glicemia a mudanças nutricionais e a sua sensibilidade ao stress (González, 2000). As concentrações plasmáticas de glicose não foram influenciadas $(\mathrm{P}>0,05)$ pela suplementação lipídica (Tabela 3). De modo geral, as suplementações lipídicas não interferiram no fornecimento da taxa de glicose ao seu organismo, pela degradação do alimento, por meio do processo digestivo em relação ao tratamento controle. Segundo Andrigueto (1990), quando o organismo recebe quantidades abundantes de glicídios alimentares, são transformados em glicose, cujo excedente é armazenado de maneira provisória na forma de glicogênio, de onde é devolvida progressivamente à circulação.

Quanto à concentração sérica de colesterol (Tabela 3), observa-se uma diferença significativa entre os níveis colesterol total dos grupos alimentados com caroço de algodão, torta de faveleira e controle $(\mathrm{P}<0,05)$. Por outro lado, os animais alimentados com a dieta sem a inclusão de lipídios apresentaram menor concentração de triglicerídeos

Tabela 2 - Consumo de matéria seca, proteína bruta e parâmetros sanguíneos de cabras leiteiras submetidas a diferentes tratamentos, na região semiárida.

\begin{tabular}{lccccc}
\hline & \multicolumn{3}{c}{ Tratamentos } \\
\cline { 2 - 6 } & TC & SF & TF & CA & CV $(\%)$ \\
\hline Matéria seca $(\mathrm{g})$ & $1,554^{\mathrm{a}}$ & $1,332^{\mathrm{b}}$ & $1,312^{\mathrm{b}}$ & $1,459^{\mathrm{ab}}$ & 5,70 \\
Matéria seca unidade metabólica $\left(\mathrm{g} / \mathrm{kg}^{0}, 75\right)$ & $95,4^{\mathrm{a}}$ & $88,9^{\mathrm{b}}$ & $83,1^{\mathrm{b}}$ & $92,6^{\mathrm{b}}$ & 5,26 \\
Proteína bruta $\left(\mathrm{g} / \mathrm{kg}^{0,75}\right)$ & $18,72^{\mathrm{a}}$ & $17,86^{\mathrm{b}}$ & $16,01^{\mathrm{c}}$ & $18,63^{\mathrm{b}}$ & 4,19 \\
Uréia $(\mathrm{mg} / \mathrm{dL})$ & 68,0 & 67,0 & 68,0 & 67,0 & 13,76 \\
Creatinina $(\mathrm{mg} / \mathrm{dL})$ & 0,58 & 0,54 & 0,60 & 0,62 & 18,54 \\
Gama glutamiltransferase (GGT/UI) & 39,25 & 43,53 & 39,25 & 40,41 & 17,52 \\
Asparto aminotransferase (AST/UI) & $73,25^{\mathrm{b}}$ & $82,91^{\mathrm{a}}$ & $79,08^{\mathrm{ab}}$ & $86,00^{\mathrm{a}}$ & 9,22 \\
Proteína total $(\mathrm{g} / \mathrm{dL})$ & $5,94^{\mathrm{b}}$ & $6,08^{\mathrm{ab}}$ & $6,34^{\mathrm{a}}$ & $6,42^{\mathrm{a}}$ & 5,18 \\
Albumina $(\mathrm{g} / \mathrm{dL})$ & $2,81^{\mathrm{b}}$ & $2,97^{\mathrm{ab}}$ & $3,03^{\mathrm{a}}$ & $2,97^{\mathrm{ab}}$ & 6,35 \\
\hline
\end{tabular}

Medias com letras diferentes na mesma linha diferem estatisticamente $(\mathrm{P}<0,05)$.

$\mathrm{TC}=$ controle; $\mathrm{SF}=$ semente de faveleira; $\mathrm{TF}=$ torta de faveleira; $\mathrm{CA}=$ caroço de algodão; $\mathrm{CV}=$ coeficiente de variação.

Tabela 3 - Concentrações séricas de glicose, colesterol total e triglicerideos de cabras leiteiras recebendo diferentes níveis de suplementação lipídica.

\begin{tabular}{lccccc}
\hline & \multicolumn{5}{c}{ Tratamentos } \\
\cline { 2 - 6 } & TC & SF & TF & CA & CV $(\%)$ \\
\hline Glicose (mg/dL) & 65.41 & 62.91 & 59.50 & 63.58 & 10,58 \\
Triglicérideos (mg/dL) & $10.41^{\mathrm{b}}$ & $14.25^{\mathrm{ab}}$ & $15.16^{\mathrm{a}}$ & $14.75^{\mathrm{a}}$ & 27,21 \\
Colesterol Total (mg/dL) & $52.75^{\mathrm{c}}$ & $70.66^{\mathrm{ab}}$ & $66.66^{\mathrm{bc}}$ & $84.33^{\mathrm{a}}$ & 20,63 \\
\hline
\end{tabular}

Médias com letras diferentes na mesma linha diferem estatisticamente $(\mathrm{p}<0,05)$.

$\mathrm{TC}=$ controle; $\mathrm{SF}=$ semente de faveleira; $\mathrm{TF}=$ torta de faveleira; $\mathrm{CA}=$ caroço de algodão; $\mathrm{CV}=$ coeficiente de variação. 
quando comparados aos que receberam torta de faveleira e caroço de algodão. Verifica-se que a maior concentração de triglicerídeo e colesterol deveu-se ao maior consumo de EE proporcionado pelas dietas, contendo semente de faveleira (SF) e caroço de algodão (CA), corroborando com o Zambom et al. (2005), quando afirma que o teor de extrato etéreo presente na dieta pode influenciar os níveis de colesterol e triglicerídeos no sangue. O que também colabora para justificar, no presente trabalho, os baixos níveis séricos de colesterol e triglicerídeos apresentados no grupo controle (Figura 1).

Na Figura 1, observam-se os níveis séricos de colesterol e triglicerídeos em função do consumo de EE das dietas experimentais tratamento controle (TC), semente de faveleira (SF), torta de faveleira (TF) e caroço de algodão (CA), nos quatro períodos experimentais.

$\mathrm{Na}$ Tabela 4, constam os resultados médios dos teores séricos de cálcio $(\mathrm{Ca})$, fósforo $(\mathrm{P})$ e magnésio $(\mathrm{Mg})$.

Os minerais representam um componente essencial na dieta de ruminantes e influenciam de modo representativo a sua produtividade, pois atuam como co-fatores essenciais para utilização de energia e proteína. Além disso, esses elementos inorgânicos não podem ser sintetizados pelo organismo animal, devendo ser fornecidos de forma balanceada na alimentação diária (Beede, 1991). Observa-se que não houve diferença significativa $(\mathrm{P}>0,05)$ nas concentrações séricas de $\mathrm{Ca}, \mathrm{P}$ e $\mathrm{Mg}$ entre os animais com adicionais de lipídios e o grupo controle. Analisando a Tabela 4, observa-se que todos os tratamentos apresentaram valores abaixo dos reportados por Boyd (1983), no que se refere aos níveis séricos de $\mathrm{Ca}$ e $\mathrm{Mg}$. Considera-se que o valor de $\mathrm{Ca}$ pode ter sido conseqüente ao início da lactação, considerando-se que neste período é esperado um balanço negativo do Ca (Ramberg Junior, 1974).

Na Figura 2, observa-se os níveis séricos de Ca e P em função do consumo de MS das dietas experimentais TC e SO (sementes oleaginosas), nos quatro períodos experimentais.

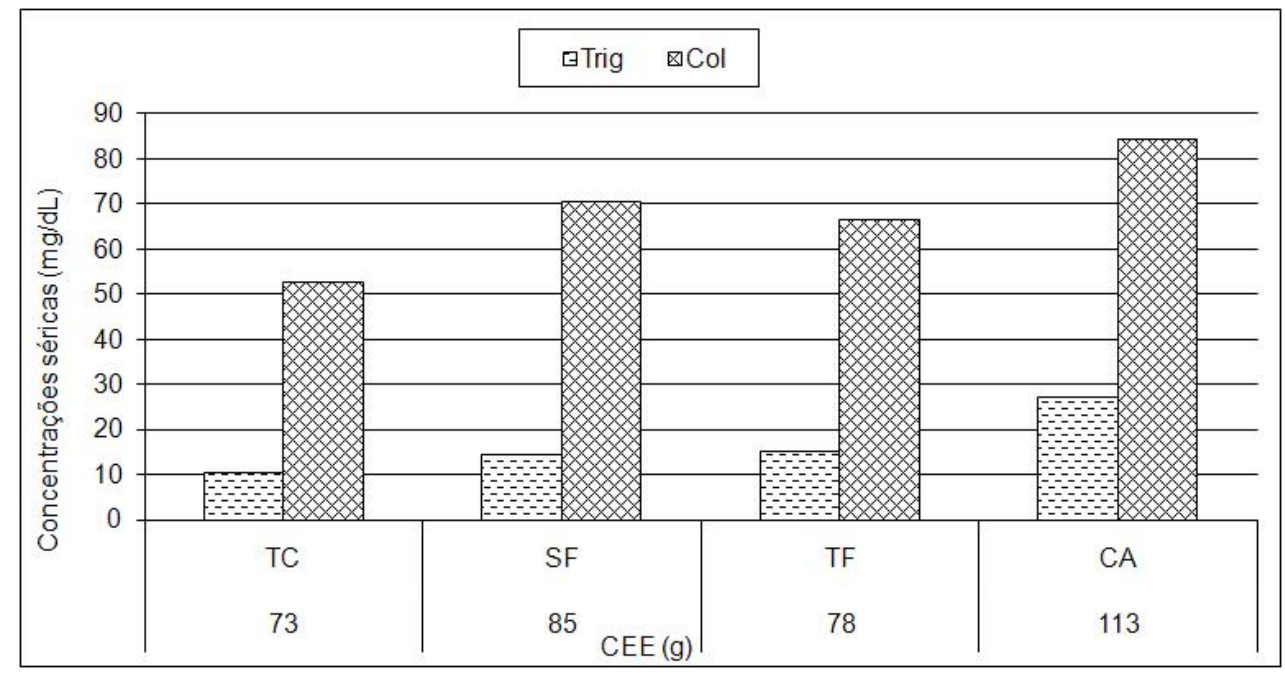

Figura 1 - Valores de colesterol e triglicerídeos em função do consumo de extrato etéreo (g).

Tabela 4 - Valores séricos de cálcio, fósforo e magnésio de cabras Saanen suplementadas com diferentes níveis de lipídios.

\begin{tabular}{lccccc}
\hline & \multicolumn{5}{c}{ Tratamentos } \\
\cline { 2 - 6 } & TC & SF & TF & CA & CV $(\%)$ \\
\hline Cálcio $(\mathrm{mg} / \mathrm{dL})$ & 6.51 & 6.45 & 6.37 & 6.21 & 10,10 \\
Fósforo $(\mathrm{mg} / \mathrm{dL})$ & 6.05 & 5.61 & 5.36 & 5.66 & 27,11 \\
Magnésio $(\mathrm{mg} / \mathrm{dL})$ & 1.91 & 1.83 & 1.99 & 1.93 & 10,80 \\
\hline
\end{tabular}

$\mathrm{TC}=$ controle; $\mathrm{SF}=$ semente de faveleira; $\mathrm{TF}=$ torta de faveleira; $\mathrm{CA}=$ caroço de algodão; $\mathrm{CV}=$ coeficiente de variação. 


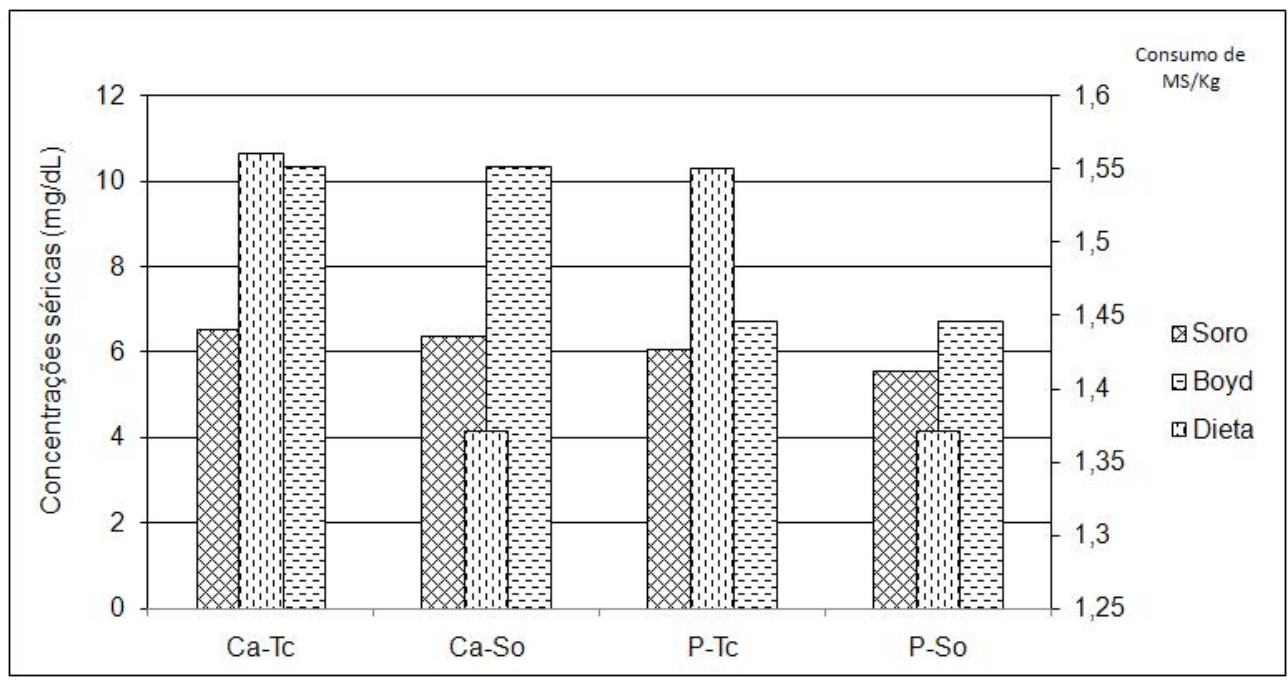

Figura 2 - Valores de Cálcio (Ca) e Fósforo (P) em função do consumo de Matéria Seca em cabras Saanen em Lactação.

Para que esses minerais sejam assimilados pelo organismo animal, é necessário seu fornecimento em um nível adequado na dieta, pois o excesso ou deficiência de um interfere na própria utilização do outro (Cavalheiro \& Trindade, 1992). Os baixos níveis de Ca podem ser decorrentes de um maior aporte de grãos na dieta, onde estes apresentam baixo e alto teor de $\mathrm{Ca}$ e $\mathrm{P}$, respectivamente. Consequentemente, elevando os níveis plasmáticos de $\mathrm{P}$.

Com relação ao magnésio, Cavalheiro \& Trindade (1992), indicam que esse mineral está envolvido com o metabolismo de carboidratos e lipídeos, sendo essencial para oxidação celular e indispensável para as atividades neuromusculares.

\section{CONCLUSÕES}

A torta de faveleira, como suplemento lipídico é a mais indicada para suplementação da dieta de cabras Saanen em lactação.

Nos níveis estudados, as fontes lipídicas não prejudicam a saúde na dieta de cabras em lactação não interferiram nas concentrações séricas de proteínas e minerais.

\section{AGRADECIMENTOS}

Ao CNPq pela bolsa de mestrado.

\section{REFERÊNCIAS BIBLIOGRÁFICAS}

AGRICULTURAL AND FOOD RESEARCH COUNCIL. The nutrition of goat. Nutrition Abstract Review (Series B), Aberdeen, v.67, n.11, 1998.
ANDRIGUETO, J.M. Nutrição animal. São Paulo: Nobel 1990. 396p.

AVILA, C.D. et al. Influences of saturation ratio of supplemental dietary fat on digestion and milk yield in dairy cows. Journal of Dairy Science, Champaign, v.83, p.1505-1519, 2001.

BEEDE, D.K. Mineral and water nutrition in dairy nutrition management. Veterinary Clinics of North America, Food Animal Practice, Philadelphia, v.7, n.2, p.373-390, 1991.

BEZERRA, G.E. Faveleira: seu aproveitamento como forrageira. Boletim Técnico, Fortaleza, v.30, n.1, jan./jun. 1972.

BOYD, J.W. The interpretation of serum biochemistry test results in domestic animals. Veterinary Clinical Pathology, v.13, p.7-14, 1983.

CAVALHEIRO, A.C.L.; TRINDADE, D.S. Os minerais para bovinos e ovinos criados em pastejo. Porto Alegre: Sagra-DC Luzzato, 1992. 141p.

CORTADA et al. Plasma urea levels on reproductive parameters of woolless rams (Ovies aires, LINNAEUS, 1758). Brazilian Journal of Veterinary Research and Animal Science, São Paulo, 2000. 
GONZÁLEZ, F.H.; SILVA, S.C. Introdução à bioquímica clínica veterinária. Porto Alegre: UFRGS, 2003. 198p.

GONZÁLEZ, F.H.D. Uso do perfil metabólico para determinar o status nutricional em gado de corte. In: GONZÁLEZ, F.H.D.; BARCELLOS, J.O.; PATIÑO, H.O.; RIBEIRO, L.A. O Perfil metabólico em ruminantes: seu uso em nutrição e doenças nutricionais. Porto Alegre: UFRGS, 2000. p.63-74.

JENKINS, T.C. Symposium: advances in ruminant metabolism: lipid metabolism in the rumen. Journal of Dairy Science, Champaign, v.76, p.3851-3863, 1993.

LAMMOGLIA, M.A. et al. Effects of dietary fat and sire breed on puberty, weight and reproductive traits of F1 beef heifers. Journal of Animal Science, Champaign, v.78, p.2244-2252, 2000.

MIR, Z. et al. Effect of feeding canola oil on constituents, conjugated linoleico acid (CLA) and long chain fatty acids in goats' milk. Small Ruminant Research, v.33, p.137-143, 1999.

MUNDIM, A.V. et al. Influência da ordem e estádios da lactação no perfil bioquímico sangüíneo de cabras da raça Saanen. Arquivo Brasileiro de Medicina Veterinária e Zootecnia, v.59, n.2, p.306-312, 2007.

RAMBERG JUNIOR, G.F. Kinetic analysis of calcium metabolism in the cow. Federation Proceedings, v.33, p.183-187, 1974.

SILVA, M.M.C. et al. Suplementação de lipídios em dietas para cabras em lactação: consumo e eficiência de utilização de nutrientes. Revista Brasileira de Zootecnia, Viçosa, v.36, n.1, p.257-267, 2007.

\section{STATISTICS ANALYSIS SYSTEMS INSTITUTE. User's} guide. North Caroline, 1999.

WITTWER, F. Diagnóstico dos desequilíbrios metabólicos de energia em rebanhos bovinos. In: GONZÁLEZ, F.H.D. et al. (Ed.).Perfil metabólico em ruminantes: seu uso em nutrição e doenças nutricionais. Porto Alegre: UFRGS, 2000. p.9-22.

ZAMBOM, M.A. et al. Ingestão, digestibilidade das rações e produção de leite de cabras saanen submetidas a diferentes relações volumoso: concentrado na ração. Revista Brasileira de Zootecnia, Viçosa, v.34, n.6, p.2505-2514, 2005. Suplemento. 